\title{
MAXIMAL AEROBIC POWER MEASUREMENT IN RUNNERS AND SWIMMERS
}

\author{
I. CORRY, BSc* and N. POWERS, MA, BChir, PhD \\ Department of Physiology, University of Edinburgh
}

\begin{abstract}
Five cross-country runners and five competitive swimmers performed a pulling exercise with elastic shock cords and a treadmill run to exhaustion. The mean $\mathrm{VO}_{2}$ max related to lean body mass of the runners was significantly higher than the swimmers on the treadmill $(p<0.05)$ while, on the pulling test, the mean $\mathrm{VO}_{2}$ max of the swimmers was significantly higher than the runners $(p<0.01)$.

The maximum heart rates achieved pulling were $95 \%$ of the running maximum by runners and $96 \%$ by swimmers with no significant difference between them. Their mean oxygen pulse was almost the same for maximal running but the swimmers had a significantly higher oxygen pulse than the runners for maximal pulling $(p<0.01)$. The swimmers could reach about $79 \%$ of their running $\mathrm{VO}_{2}$ max by pulling while the runners used $53 \%$ of their running $\mathrm{VO}_{2}$ max.
\end{abstract}

Key words: Maximum oxygen uptake, Swimmers, Runners, Arm ergometry, Treadmill running.

\section{INTRODUCTION}

Maximal aerobic power (MAP) which is expressed as $\mathrm{VO}_{2}$ max (Hermansen, 1973) is the best laboratory measurement of an individual's capacity for prolonged heavy work (Åstrand and Rodahl, 1977; Harrison et al, 1980; Robinson, 1980) since there is a strong positive correlation between $\mathrm{VO}_{2}$ max and physical work capacity (De Vries, 1977; Taylor et al, 1962). As an estimate of fitness it ignores strength, agility, motivation and technique, but it is indicative of the functional state of the respiratory, circulatory and metabolic systems (Hermansen, 1977; Nagle, 1973).

In evaluation of MAP in athletes it becomes important to select a work situation which allows optimal use of specifically trained muscle fibres (Stromme et al, 1977). So, instead of using a generalised "whole body" $\mathrm{VO}_{2} \max$, the $\mathrm{VO}_{2}$ max for a specified exercise may be a more useful measurement in estimation of a specifically trained athlete's performance potential, even if it is a lower value than the $\mathrm{VO}_{2}$ max measured using a larger muscle mass but including muscles not so highly trained.

A swimmer is a good example of a specifically trained athlete whose $\mathrm{VO}_{2}$ max during swimming is difficult to measure, while $\mathrm{VO}_{2} \max$ for treadmill running or cycling includes the use of muscles untrained in those activities. That intensive swim training need not be linked to any increase in $\mathrm{VO}_{2}$ max running has been suggested (Holmer, 1974; McArdle et al, 1978; Magel et al, 1975) nor is running an effective modality to enhance MAP for swimming (McArdle et al, 1978).

A form of land ergometry using the swimming style

- Present Address:

2 Cardigan Drive,

BELFAST, BT14 6LX pulling exercise is sure to involve swimmers' muscles in a similar role to in the water and might be useful in monitoring the changes in a swimmer's arobic power during the course of a training programme. The widely documented arm cranking (e.g. Vokac et al, 1975) is an activity unrelated to swimming but we suggest that pulling as performed in this study utilises the prime movers of the swimmers upper body. We have seen only one other study using swimming-style pulling technique, but the pulling movement was not standardised - "each swimmer simulated his principal competitive stroke" and no comparison was made with other sportsmen or non-athletes (Armstrong and Davies, 1981).

In this study, the aerobic power of swimmers and runners is compared by tests related to their respective disciplines, running for the runners and pulling for the swimmers. By these tests their specific adaptations can be shown and the usefulness of the pulling test for swimmers may be established.

Having shown the adaptation of swimmers to this test, confirming our views, the next stage would be to examine the aerobic power of swimmers swimming and correlate this with their $\mathrm{VO}_{2}$ performance pulling; this has not yet been done.

\section{SUBJECTS}

Five cross-country runners, and five competitive swimmers, three men and two women in each group (see Table 1), were invited to participate in two types of ergometry, to investigate the specificity of their aerobic power to running or pulling.

\section{APPARATUS}

Running was performed on a Morgan treadmill inclined at $7^{\circ}, 12.2 \%$ and the speed was varied. 


\section{TABLE I}

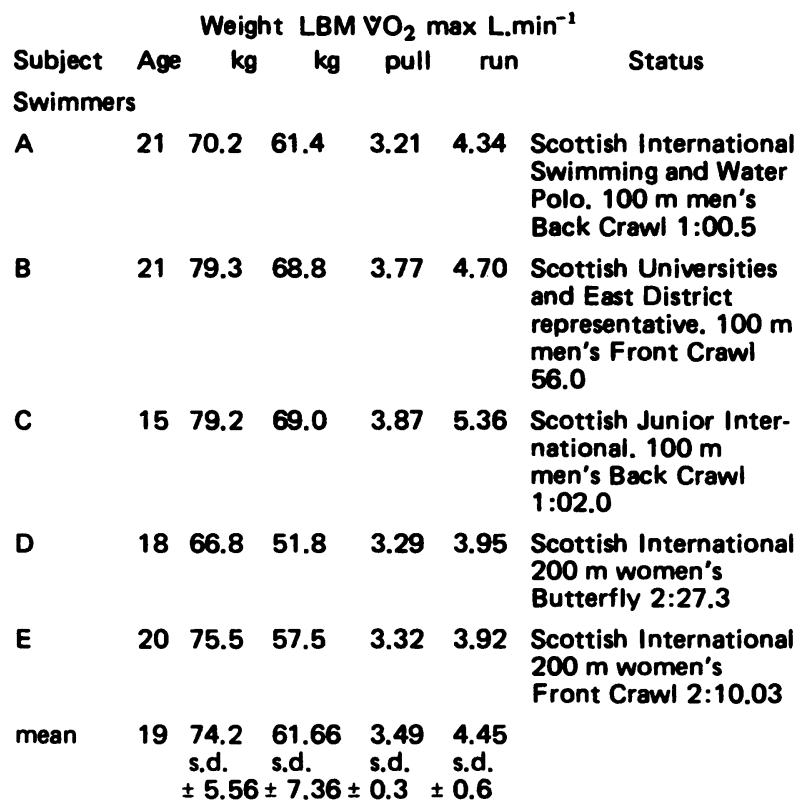

Runners

\begin{tabular}{|c|c|c|c|c|c|c|}
\hline G & 19 & 71.7 & 63.9 & 2.92 & 4.79 & $\begin{array}{l}\text { N. Ireland AAA Junior } \\
\text { representative. 10th } \\
\text { British Junior in } \\
\text { men's } 3000 \mathrm{~m} \text { steeple- } \\
\text { chase. }\end{array}$ \\
\hline H & 18 & 60.5 & 53.4 & 2.49 & 4.55 & $\begin{array}{l}\text { British Junior men's } \\
\text { orienteering champion } \\
\text { men's }\end{array}$ \\
\hline $\mathbf{J}$ & 20 & 52.2 & 48.0 & 2.30 & 3.54 & $\begin{array}{l}\text { Men's Scottish } \\
\text { Universities and } \\
\text { English County repre- } \\
\text { sentative }\end{array}$ \\
\hline$K$ & 24 & 58.2 & 47.1 & 1.69 & 4.11 & $\begin{array}{l}\text { Women's Scottish } \\
\text { International } 1500 \mathrm{~m} \text {, } \\
3000 \mathrm{~m} \text {, and cross- } \\
\text { country }\end{array}$ \\
\hline $\mathbf{L}$ & 20 & 53.0 & 45.0 & 1.69 & 3.75 & $\begin{array}{l}\text { Women's Scottish } \\
\text { International cross- } \\
\text { country representa- } \\
\text { tive }\end{array}$ \\
\hline mean & 20 & $\begin{array}{l}59.12 \\
\text { s.d. } \\
\pm 7.85\end{array}$ & $\begin{array}{l}51.48 \\
\text { s.d. } \\
\pm 7.6\end{array}$ & $\begin{array}{l}2.22 \\
\text { s.d. } \\
0.53\end{array}$ & $\begin{array}{l}4.15 \\
\text { s.d. } \\
0.53\end{array}$ & \\
\hline
\end{tabular}

Pulling was tested using elastic shock cords at the rate set by a metronome. On the inspiratory side, a pneumotachograph integrator (Mercury electronics CS5) recorded tidal volume, the air being inhaled via corrugated tubing vol. $500 \mathrm{~cm}^{3}$. The mouthpiece for pulling was a Siebe-Gorman valve while for running a perspex low resistance valve was used similar to the design of
Programme: Sample of calculation by the HewlettPackard

\section{O2 CONSUMPTION RQ \& ENERGY EXPENDITURE}

$\begin{array}{lc}\text { TIME MIN. SEC? } & 0.20 \\ \text { I.E. } & 0.33 \mathrm{MIN} \\ \text { FINAL LITRES? } & 100.00 \\ \text { INITIAL LITRES? } & 60.00 \\ & 40.00 \\ \text { GAS TEMP? } & 21.00 \mathrm{DEG} \\ \text { METER CORRECTION FACTOR? } & 0.98 \\ \text { BAR P? } & 100.60 \mathrm{KPA} \\ \text { VAP } P=2.5 \mathrm{KPA} & \\ \text { CO2 } \% ? & \\ \text { O2\% } & 4.00 \\ \text { V DOT }=105.741 / \mathrm{MI} \leftarrow \mathrm{V} & 17.00 \\ \text { O2 INHALED }=22.12 \mathrm{~L} / \mathrm{MIN} & \\ \text { O2 EXHALED }=17.98 \mathrm{~L} / \mathrm{MIN} & \\ \text { O2 CONSUMPTION }=4.14 \mathrm{~L} / \mathrm{MIN} \leftarrow \mathrm{VO}_{2} \\ \text { CO2 EXHALED }=4.20 \mathrm{~L} / \mathrm{MIN} \leftarrow \mathrm{VCO}_{2} \\ \text { RQ }=1.01 \leftarrow \text { R. } 0 . \\ \text { POWER }(W E I R)=1430 \mathrm{~W}\end{array}$

OTIS and MACKERIS (Åstrand and Rodahl, 1977). Expiratory gas was collected after passing through an external dead space of $850 \mathrm{~cm}^{3}$ (pulling), $880 \mathrm{~cm}^{3}$ (running) in Douglas bags via a 3-bag changing junction.

Heart rate was calculated from three ECG leads and a pneumotachograph trace was also plotted on the same recording.

Gas analysis was performed by blowing the gas through a dry gas meter previously calibrated. Samples of dried gas from the bags were analysed for carbon dioxide and oxygen previously calibrated using standard gases and checked against the atmosphere between every sample analysis.

Using the gas reading, its correction factor, $\% \mathrm{CO}_{2}$, $\mathrm{\% O}_{2}$, barometric pressure and room temperature, the data shown on the computer print out, illustrated in Fig. 2, were calculated on a Hewlett HP 981 5A calculator. On this, the vapour pressure was calculated using an algorithm accurate in the range $8^{\circ}-37^{\circ}$ and leaving an error from this source of $0.1 \%$ in the results.

Skin folds to estimate \% fat and hence LBM were taken using Harpenden skin fold calipers and compared with the Durnin and Womersley Nomogram allowing an error of $\pm 3.5 \% \%, \pm 5 \%$ o (Durnin and Womersley, 1974).

The statistical analysis was by the Unpaired Students $t$-test, with significance assumed at $p<0.05$. 


\section{ERGOMETRY}

The running test was of the continuous type, the speed being increased until the subject was unable to continue; the gradient remained at $7^{\circ}$ (Fig. 1). After a warm-up of stretching exercises and a jog on the treadmill at 6-8 kph without a mouthpiece, the subject ran at two submaximal speeds, the aims of which were 3-fold.

1. A warm-up for the subject under experimental conditions.

2. Using the heart rate achieved, the experimenter calculated speeds likely to give heart rates of 150 , 170 and maximum for the first three stages of the test.

3. The subject practised stopping the treadmill by a red button in front of him or by pulling on his safety harness.

After a 10-15 min rest in an armchair the test began, protocol Fig. 2. Speed one was aimed to give a HR 150, speed two 170. Speed three, etc. were increased at the same increment until exhaustion.

The pulling was performed using elastic shock cords after a warm-up of stretching and two practice periods on the cords. The subject was standing, leaning forward and pulling from arm's length, at the point where the cords just became tense to the outside of the thigh (Fig. 3). This meant that the subject's reach determined his workload; the shock cord tension and the range for each subject are shown in Fig. 4. The rate of pulling, alternate right arm left arm, was determined by a metronome at three settings (Protocol, Fig. 5).

Exhaustion was determined by an observer when it became clear that the subject, although maintaining the correct rate, could no longer pull the handle back to his thigh.

$\mathrm{VO}_{2}$ max was the highest $\mathrm{VO}_{2}$ achieved during the course of the test, measured from expired gas collected during 20 second periods in Douglas bags. Examples of the time course for reaching $\mathrm{VO}_{2}$ max are shown graphically in Fig. 6.

In both tests, the cumbersome nature of the gas collecting apparatus and the inexperience of the athletes in performing the exercises may have introduced some individual variation related to each person's adaptation to the novel situation. This cannot be quantified.

\section{DISCUSSION}

$\mathrm{VO}_{2}$ max for arm cranking has been shown to be $68 \%$ to $78 \%$ of the $\mathrm{VO}_{2}$ max for leg work in unathletic subjects (Reybrouck et al, 1975; Vokac et al, 1975). Our results show that the runners could reach $41 \%$ to $64 \%$ of their running $\mathrm{VO}_{2} \max$ in the pulling exercise;

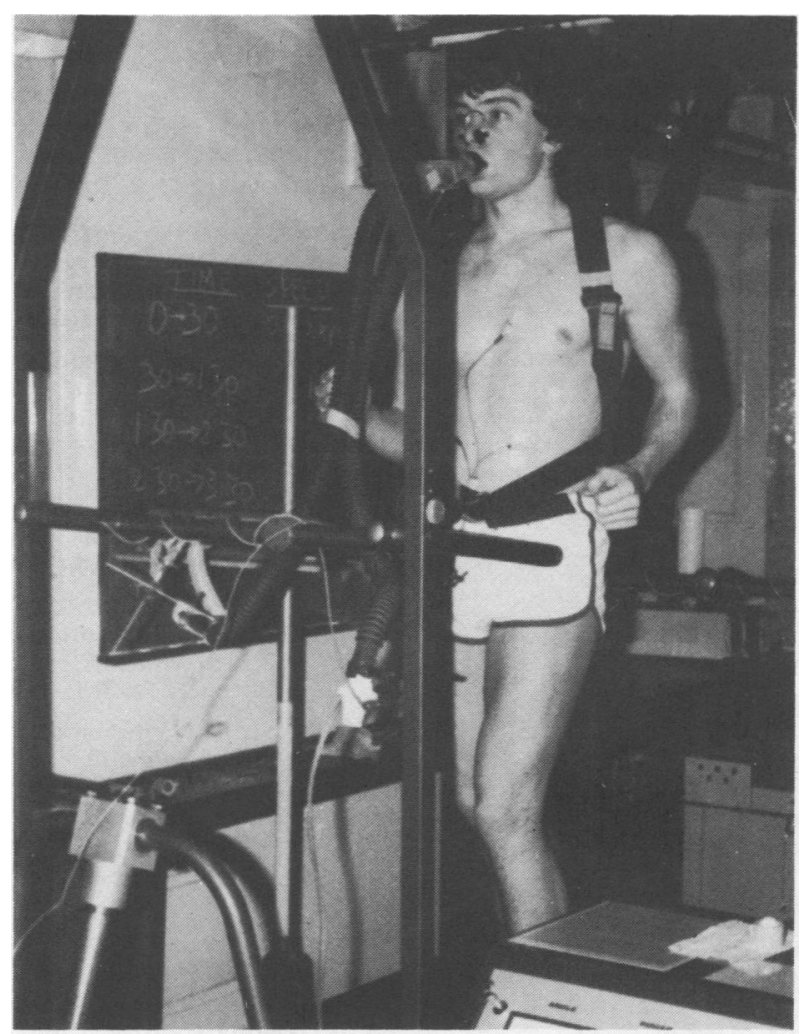

Fig. 1. The pneumotachograph transducer is on the inspiratory side. The expiratory side goes to a Douglas bag via the changing junction. The safety harness activates a cut-out in the event of a fall. Position of ECG leads - running: sternal angle and left at the 9th intercostal space, in mid-clavicular line (earth on right ribs).

they reached a mean of 53\%. The swimmers reached $72 \%$ to $85 \%$, with a mean of $79 \%$. The figures differ at the 0.001 level of significance.

The heart rates were much closer, runners attaining $91 \%$ to $103 \%$ of their running rate by pulling, mean 95\%; similarly the swimmers attained $93 \%$ to $98 \%$, mean $96 \%$.

Oxygen pulse, the volume of oxygen consumed per heart beat, is where the most clear-cut difference between the groups is seen. In running, the $\mathrm{O}_{2}$ pulse max was $23 \mathrm{ml} / \mathrm{beat}$ for the runners and 24 for the swimmers, while in pulling the runners dropped to 13 and the swimmers to 20 , the difference between the groups being significant at the 0.01 level for pulling, but the same for running.

These results (Fig. 7) show a negative correlation $r=0.68, p<0.05$. This may be due to a number of 


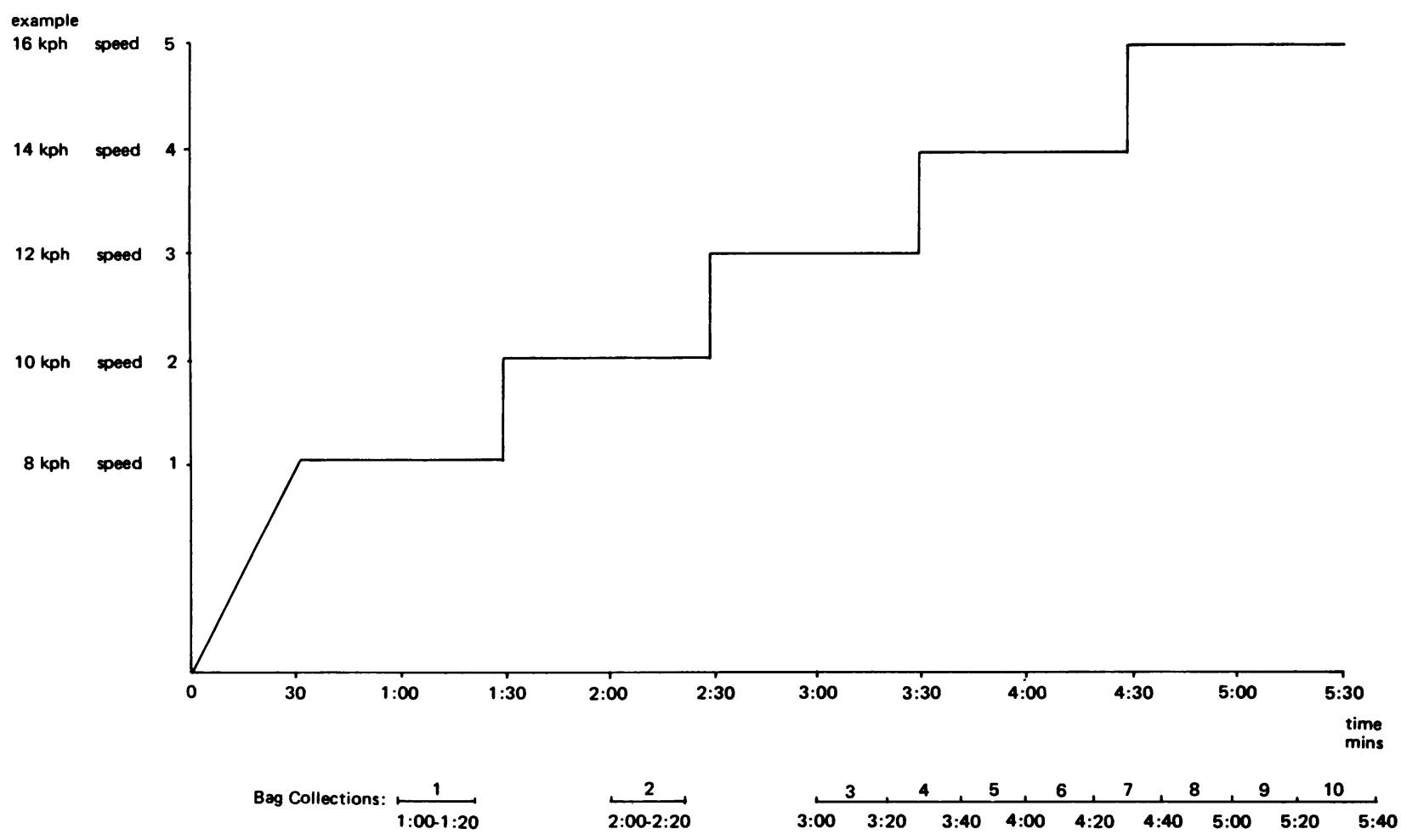

All subjects stopped between 3:25 and 5:25

Fig. 2.

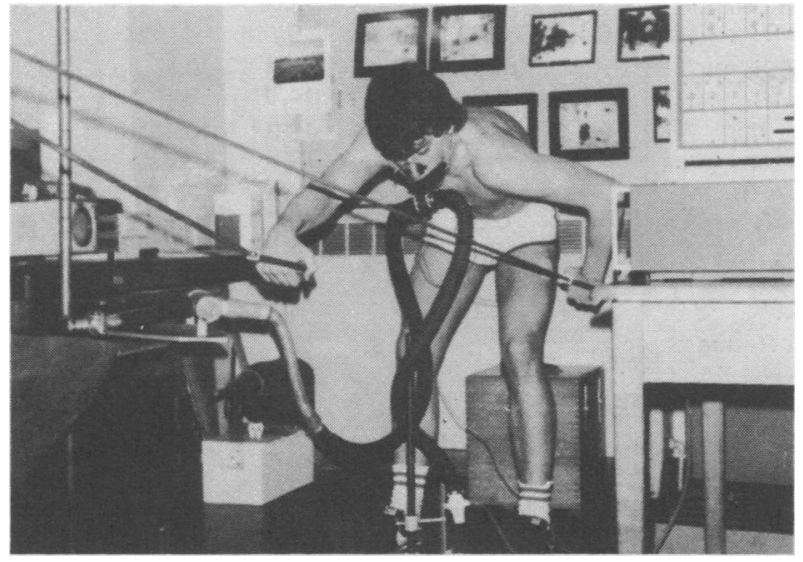

Fig. 3. Shock cords are pulled alternating right arm-left arm from arms length to outside of the thigh at a rate set by a metronome.

Note ECG connection on left thigh and sternal angle (earth on right ribs) and pneumotachograph transducer on inspiratory side.

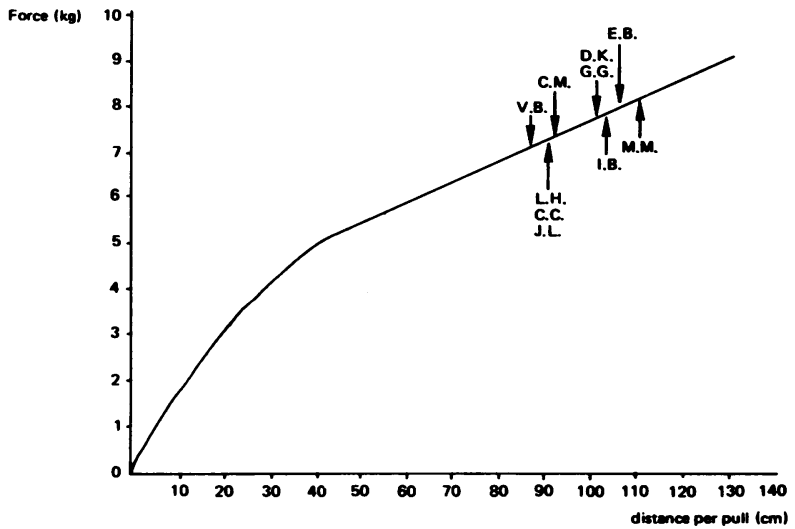

Fig. 4. Length-tension curve for shock cords.

points, but the main contributing factor is the biased nature of the groups, swimmers having been trained with arm work predominating, whereas running is a leg dominated activity. While $\mathrm{VO}_{2}$ max measured using any standard ergometer may indicate general MAP in untrained or non-specifically trained subjects, performance in one test should not be correlated with another in 


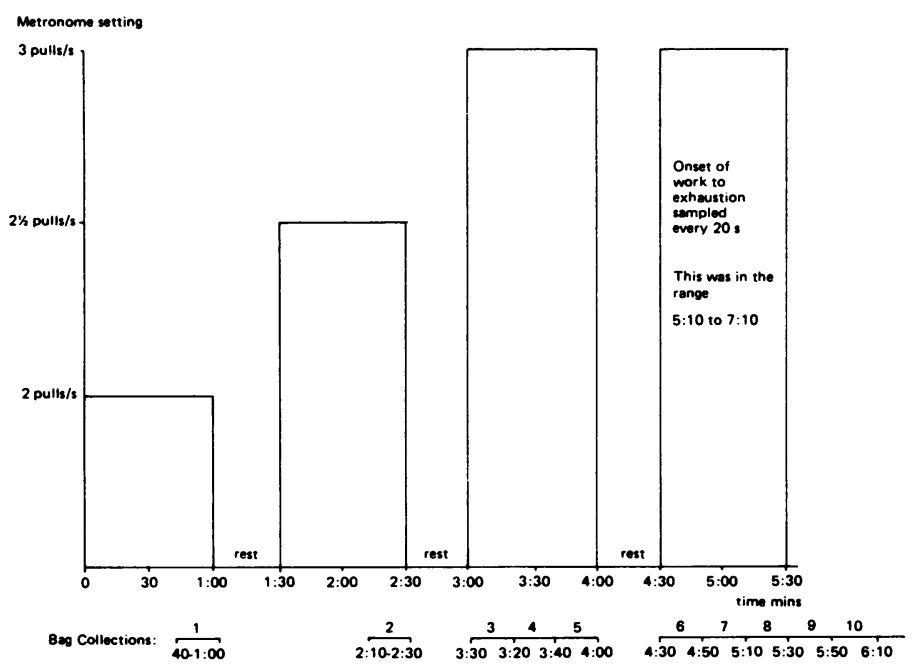

Fig. 5. Pulling ergometry.

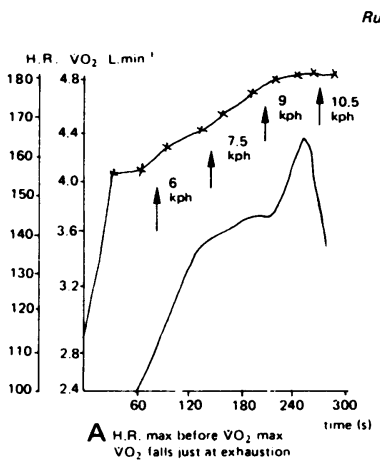

Running

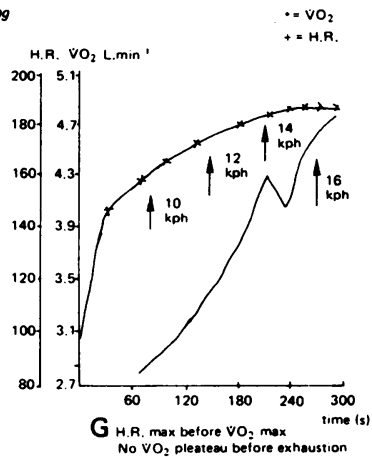

Last phase of pulling

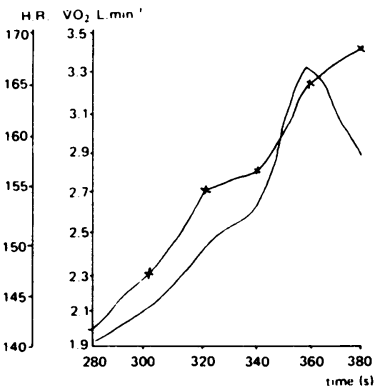

Evo, max betore H. R. max

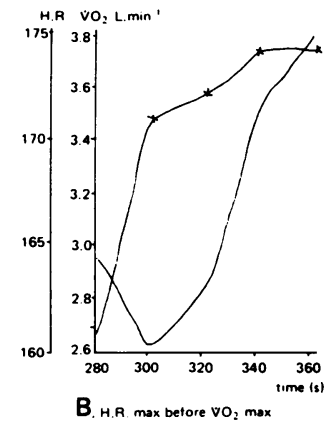

Fig. 6

those athletes specifically trained to do either. This confirms the view that for such athletes one is not justified in generalising from one $\mathrm{VO}_{2} \max$ value to a theoretical whole body MAP (Bouchard et al, 1979).
TABLE II

Table of mean values

\begin{tabular}{|c|c|c|c|c|c|}
\hline \multirow{2}{*}{\multicolumn{2}{|c|}{$\begin{array}{c}\text { running } \\
\text { swim- } \\
\text { runners mers }\end{array}$}} & \multicolumn{4}{|c|}{ pulling } \\
\hline & & $\begin{array}{l}\text { signifi- } \\
\text { cance }\end{array}$ & runners & $\begin{array}{c}\text { swim- } \\
\text { mers }\end{array}$ & $\begin{array}{l}\text { signifi- } \\
\text { cance }\end{array}$ \\
\hline $\begin{array}{l}4.15 \\
0.53\end{array}$ & $\begin{array}{l}4.5 \\
0.6\end{array}$ & N.S. & $\begin{array}{l}2.2 \\
0.5\end{array}$ & $\begin{array}{l}3.5 \\
0.3\end{array}$ & 0.01 \\
\hline 70.24 & 59.98 & $0<0.01$ & 37.4 & 47.1 & $p<0.02$ \\
\hline
\end{tabular}

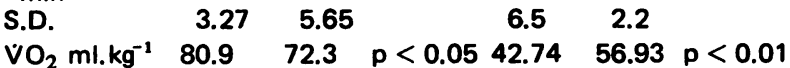

LBM min $^{-1}$

S.D.

$6.1 \quad 4.42$

4.42

$V_{e}$ L. $\min ^{-1} \quad 107.5 \quad 106.5$

s.b.

5.5

$V_{f} \min ^{-1} \quad 50.4 \quad 43.4$

$\begin{array}{lrr}\text { s.b. } & 9.3 & 9.5\end{array}$

$\begin{array}{lll}\text { T.V.L } & 2.2 & 2.5\end{array}$

S.D.

0.6

2.5
0.5

$\mathrm{V}_{8 \mathrm{q}} \mathrm{L}(100 \mathrm{ml}) \quad 2.4 \quad 2.6$

$\begin{array}{lll}\text { S.D. } & 0.29 & 0.25\end{array}$

H.R. $\min ^{-1} 181 \quad 186$

S.D.

$6 \quad 6$

$\mathrm{O}_{2}$ pulse

$22.9 \quad 23.9$

S.D.

2.4

3.1
N.S. $\quad 67.4 \quad 89.2$
$14.0 \quad 9.0$

N.S. $\quad 49.3 \quad 40.1$

6.7

N.S. $\quad 1.45 \quad 2.28 p<0.02$

$\begin{array}{lll} & 0.3 & 0.5\end{array}$

N.S. $\quad 3.1 \quad 2.6 \quad p<0.05$

$0.3 \quad 0.36$

N.S. $172 \quad 179 \quad$ N.S.

$\begin{array}{llll} & 12 & 7 & \\ \text { N.S. } & 12.9 & 19.6 & p<0.01\end{array}$

$$
2.6 \quad 1.7
$$

However, the value of more specific quantification of $\mathrm{VO}_{2}$ max for a certain exercise has been shown, and although not enough swimmers who swim the same events have been tested to find a correlation between $\mathrm{VO}_{2}$ max pulling and swimming performance, the test could be used longitudinally to monitor change in swimming fitness with time as it is evident that swimming training does cause major adaptation in favour of this 


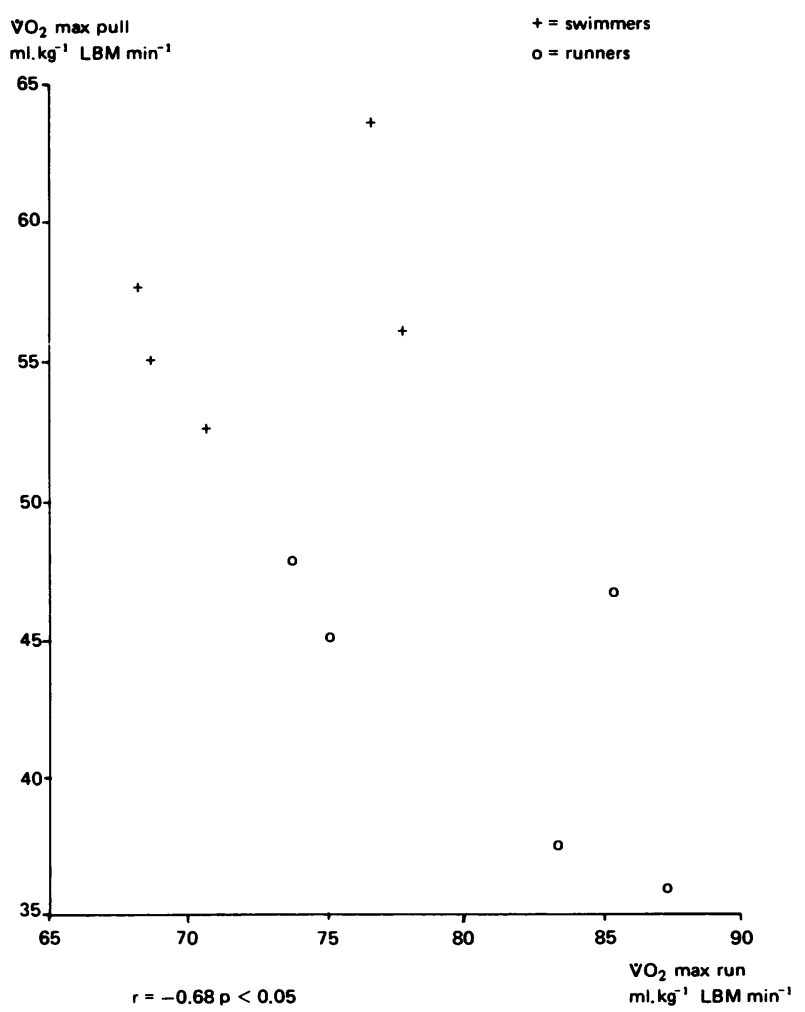

Fig. 7. $\mathrm{VO}_{2}$ max pull against $\mathrm{VO}_{2} \max$ run.

type of work. Those who say that swimmers' $\mathrm{VO}_{2}$ max should not be specified for body weight since they do not carry their body weight swimming (Armstrong and Davies, 1981; Faulkner, 1968; Holmer, 1974; Holmer et al, 1974), fail to separate a large $\mathrm{VO}_{2} \max$ due to large size from a large $\mathrm{VO}_{2} \max$ due to efficient adaptation. The favoured expression in this study is ml. $\mathrm{kg}^{-1}$ (LBM) $\mathrm{min}^{-1}$ since it most nearly quantifies the $\mathrm{O}_{2}$-consuming mass, although mass of active tissue, rather than LBM would be even better (Buskirk and Taylor, 1957).

\section{CONCLUDING REMARKS}

While pulling ergometry is not suitable for measuring absolute $\mathrm{VO}_{2}$ max, it may be a more meaningful test for swimmers whose training involves mostly upper body conditioning, and for whom any leg training is done in a manner quite different from running or cycling. Thus $\mathrm{VO}_{2}$ max pulling with the pulling exercise specified could be used longitudinally to study the effects of a training programme and possibly for prediction of likely swimming performance.

Achievements by swimmers on the pulling test bore no relationship to their running $\mathrm{VO}_{2}$ max, nor did the runners show correlation between their running and pulling.

For any sport, the ergometry should be closely related to the training and less emphasis be placed on absolute $\mathrm{VO}_{2}$ max than the $\mathrm{VO}_{2}$ max attained for a specific test relevant to the sport in question.

\section{ACKNOWLEDGEMENTS}

Gratitude is expressed to Mr. Alan Rainer, the Physiology Department, the swimmers and runners for $\infty$ operation and assistance.

\section{REFERENCES}

Armstrong, N. and Davies, B., 1981 "An ergometric analysis of age group swimmers". Brit.J.Sports Med. 15: 20-26.

Åstrand, P.-O. and RodahI, K., 1977. Textbook of Work Physiology. McGraw-Hill: New York.

Bonen, A., Wilson, B. A., Yarkony, M. and Belcastro, A. N., 1980 "Maximal oxygen uptake during free, tethered and flume swimming". J.Appl.Physiol. 48: 232-235.

Bouchard, C., Godbout, P., Mondor, J.-C. and Leblanc, C., 1979 "Specificity of maximal aerobic power". Eur.J.Appl. Physiol. 40: 85-93.

Buskirk, E. and Taylor, H. L., 1957 “Maximal oxygen intake and its relation to body composition, with special reference to chronic physical activity and obesity". J.Appl.Physiol. 11: 72-78.

De Vries, H. A., 1977. Physiology of Exercise. W. C. Brown.

Durnin, J. V. G. A. and Womersley, J., 1974 "Body fat assessed from total body density and its estimation from skinfold thickness. Measurements on 481 men and women aged from 16 to 72 years". Brit.J.Nutr. 32: 77-97. 
Faulkner, J. A., 1968 “Physiology of swimming and diving”. In: Exercise Physiology, Ed. H. B. Falls. Academic Press, New York.

Harrison, M. H., Brown, G. A. and Cochrane, L. A., 1980 "Maximal oxygen uptake: its measurement, application and limitations". Aviat.Space Environ.Med. 51: 1123-1127.

Hermansen, L., 1973 “Oxygen transport during exercise in human subjects”. Acta Physiol.Scand. Supp. 399.

Holmer, I., 1974 "Physiology of swimming man". Acta Physiol.Scand. Supp. 407.

Holmer, I. and Åstrand, P.-O., 1972 "Swimming training and maximal oxygen uptake". J.Appl.Physiol. 33: 510-513.

Holmer, I., Lundin, A. and Eriksson, B. O., 1974 "Maximal oxygen uptake during swimming and running by elite swimmers". J.Appl.Physiol. 36: 711-714.

Magel, J. R., Foglia, G. F., McArdle, W. D., Gutin, B., Pechar, G. S. and Katch, F. I., 1975 “Specificity of swim training on maximum oxygen uptake". J.Appl.Physiol. 38: 151-155.

McArdle, W. D., Magel, J. R., Delio, D. J., Toner, M. and Chase, J. M., 1978 "Specificity of run training on $\mathrm{VO}_{2} \max$ and heart rate changes during running and swimming". Med.Sci.Sports 10: 16-20.

Nagle, F. J., 1973 “Physiological assessment of maximal performance”. In: Exercise and Sports Science Review Vol. 1. Ed. Wilmore.

Reybrouck, T., Heigenhauser, G. F. and Faulkner, J. A., 1975 “Limitations to maximum oxygen uptake in arm, leg, and combined arm-leg ergometry". J.Appl.Physiol. 38: 774-779.

Robinson, S., 1980 "Physiology of muscular exercise”. In: Medical Physiology. Ed. Mountcastle, V. B., Vol. 2. C. V. Mosby: New York.

Stromme, S. B., Ingjer, F. and Meen, H. D., 1977 "Assessment of maximal aerobic power in specifically trained athletes". J.Appl.Physiol. 42: 833-837.

Taylor, H. L., Yang Wang, Rowell, L. and Blomquist, G., 1962 "The standardisation and interpretation of submaximal and maximal tests of working capacity". Paed. 32: 703-720.

Vokac, Z., Bell, H., Bautz-Holter, E. and Rodahl, K., 1975 “Oxygen uptake/heart rate relationship in leg and arm exercise, sitting and standing". J.Appl.Physiol. 39: 54-59. 